\title{
A portable lightweight in situ analysis (LISA) box for ice and snow analysis
}

\author{
Helle Astrid Kjær ${ }^{1}$, Lisa Lolk Hauge ${ }^{1}$, Marius Simonsen ${ }^{1}$, Zurine Yoldi ${ }^{1}$, Iben Koldtoft ${ }^{1}$, Maria Hörhold ${ }^{2}$, \\ Johannes Freitag $^{2}$, Sepp Kipfstuhl ${ }^{1,2}$, Anders Svensson ${ }^{1}$, and Paul Vallelonga ${ }^{1,3}$ \\ ${ }^{1}$ Physics of Ice, Climate and Earth (PICE), Niels Bohr Institute, University of Copenhagen, Copenhagen, Denmark \\ ${ }^{2}$ Alfred-Wegener-Institut, Helmholtz-Zentrum für Polar- und Meeresforschung, Bremerhaven, Germany \\ ${ }^{3}$ UWA Oceans Institute, The University of Western Australia, Crawley, WA, Australia
}

Correspondence: Helle Astrid Kjær (hellek@fys.ku.dk)

Received: 10 February 2021 - Discussion started: 2 March 2021

Revised: 1 June 2021 - Accepted: 10 June 2021 - Published: 11 August 2021

\begin{abstract}
There are enormous costs involved in transporting snow and ice samples to home laboratories for "simple" analyses in order to constrain annual layer thicknesses and identify accumulation rates of specific sites. It is well known that depositional noise, incurred from factors such as wind drifts, seasonally biased deposition and melt layers can influence individual snow and firn records and that multiple cores are required to produce statistically robust time series. Thus, at many sites, core samples are measured in the field for densification, but the annual accumulation and the content of chemical impurities are often represented by just one core to reduce transport costs. We have developed a portable "lightweight in situ analysis" (LISA) box for ice, firn and snow analysis that is capable of constraining annual layers through the continuous flow analysis of meltwater conductivity and hydrogen peroxide under field conditions. The box can run using a small gasoline generator and weighs less than $50 \mathrm{~kg}$. The LISA box was tested under field conditions at the East Greenland Ice-core Project (EastGRIP) deep ice core drilling site in northern Greenland. Analysis of the top $2 \mathrm{~m}$ of snow from seven sites in northern Greenland allowed the reconstruction of regional snow accumulation patterns for the 2015-2018 period (summer to summer).
\end{abstract}

\section{Introduction}

To evaluate future sea level changes, surface mass balance (SMB) determinations of the major ice sheets and ice caps are an important constraint. Theoretical predictions regard- ing the change in SMB are made based on advanced ice sheet models, but they also rely on accurate accumulation estimates from past periods (Montgomery et al., 2018). Accumulation of the past can be reconstructed by means of ice and firn core analysis. To estimate ice core ages, chemical profiles are often used to generate annually resolved timescales (Winstrup et al., 2012; Svensson et al., 2008). However, ice cores are spatially limited for practical reasons: drilling campaigns of deep ice cores are expensive, as they require the maintenance of large-scale facilities for several years; drilling campaigns of shorter snow and firn cores are cheaper, although they are still costly in terms of time and money.

Having retrieved such snow/firn cores, annual layers and accumulation rates can be directly reconstructed by investigating the chemical impurities within the ice. Several of these impurities have annual cycles in Greenland snow and ice - for example, insoluble dust particles and calcium peak in early spring as a result of increased storm activity, acids peak in spring time following the Arctic haze phenomenon and higher signals are observed with acid from volcanic eruptions, and hydrogen peroxide is driven by light processes and peaks in midsummer (Gfeller et al., 2014; Legrand and Mayewski, 1997). Using one or more profiles of an ice core site, an accurate timescale can be established by dating and, if the density is also measured, the local accumulation rate of a site can be reconstructed (Winstrup et al., 2019; Philippe et al., 2016).

The chemical profiles in ice cores can be obtained by means of continuous flow analysis (CFA), a fast way to obtain high-resolution chemical profiles, performed in home 
laboratories (Kaufmann et al., 2008; Bigler et al., 2011; Dallmayr et al., 2016). A generic CFA consists of a melt head, which splits the sample stream into an inner uncontaminated line and an outer possibly contaminated line. The inner line is then split further, allowing a small amount of sample water for each analytical measurement. Field campaigns with incamp melting and CFA are not carried out on a routine basis, as the analytical set-ups require space, time and warm laboratories on-site (Schüpbach et al., 2018). Thus, these campaigns are limited to larger ice core drilling stations in Greenland (NEEM community members et al., 2013) and Antarctica where heavy and delicate instruments can be flown in and out by large cargo aircraft, and warm buildings or areas exists with space enough to construct a laboratory.

Here, we have developed a truly field-portable CFA setup that can determine annual layers in snow and firn. We developed a system that is optimized for deep field deployment, which can be powered by a small gasoline generator and operated in below-zero conditions. In addition, we made it lightweight enough to be transported in the field by two people. As time in the deep field is often limited, we also aimed for a device that provides results quickly (so that the spatial variability at a site can be investigated within a day of field work) as well as an instrument that can be used by laypeople.

In the summers of 2017 and 2019, we demonstrated the LISA box under Greenland field conditions at the East Greenland Ice-core Project (EastGRIP) ice core drilling site (see map Fig. 1) by reconstructing accumulation from snow cores covering the top $2 \mathrm{~m}$ of snowpack. Although the LISA box may be used to melt ice cores, we will focus on the application to snow and firn.

\section{Materials and methods}

The LISA box is a small CFA system set up to melt snow, firn and ice cores and to analyse the meltwater for conductivity and hydrogen peroxide.

Overall, it consists of a square foam box with a lid that provides insulation against external conditions. The outer dimensions of the box are $0.585 \mathrm{~m}$ (height) $\times 0.475 \mathrm{~m}$ (width) $\times 0.765 \mathrm{~m}$ (length). The foam is $10 \mathrm{~cm}$ thick, making the respective inner dimensions $0.35 \mathrm{~m} \times 0.35 \times 0.58 \mathrm{~m}$. A circular melt head is placed in the lid; inside the box, which is temperature controlled, a small version of a CFA system is set up, including a miniature computer for instrument control and storage (see Fig. 2).

Some additional components are required outside the LISA box: a handheld generator for power, a wastewater container and pump, and a screen and keyboard for easy instrument adjustments. The LISA box is presented in more detail in the following.

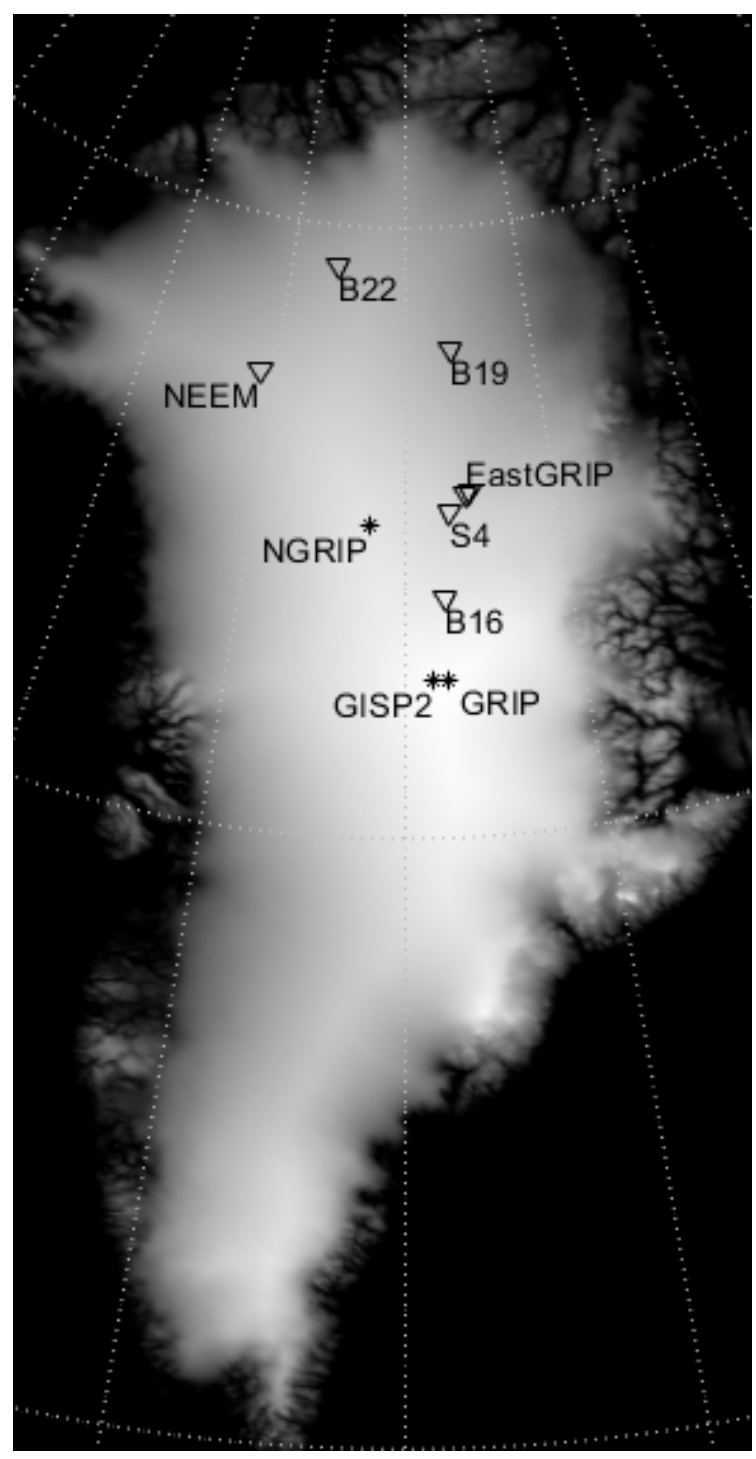

Figure 1. Position of the sites studied using the LISA box (triangles). The asterisks indicate deep ice core drilling sites. Note that two sites (S5 and S7) were investigated at EastGRIP. The background altitude map of Greenland is based on the SeaRISE dataset (Bamber, 2001; Bamber et al., 2001).

\subsection{Melt head and melt speed registration}

The melt head (shown as "A" in Fig. 2 and outlined in Fig. S2 in the Supplement), which is used to melt the snow, firn or ice sample, is placed in the lid of the foam box and reaches both the inner and outer side of the foam box with the intention that the sample is melted on the outside while meltwater is transported into the box for further analysis.

The melt head is circular to allow for the analysis of fullsized snow and ice cores to avoid time-consuming cutting in the field. The melt head has an inclined surface to divert the outer part of the melted core to waste as well as an inner inclined conical surface for the collection of the sample 

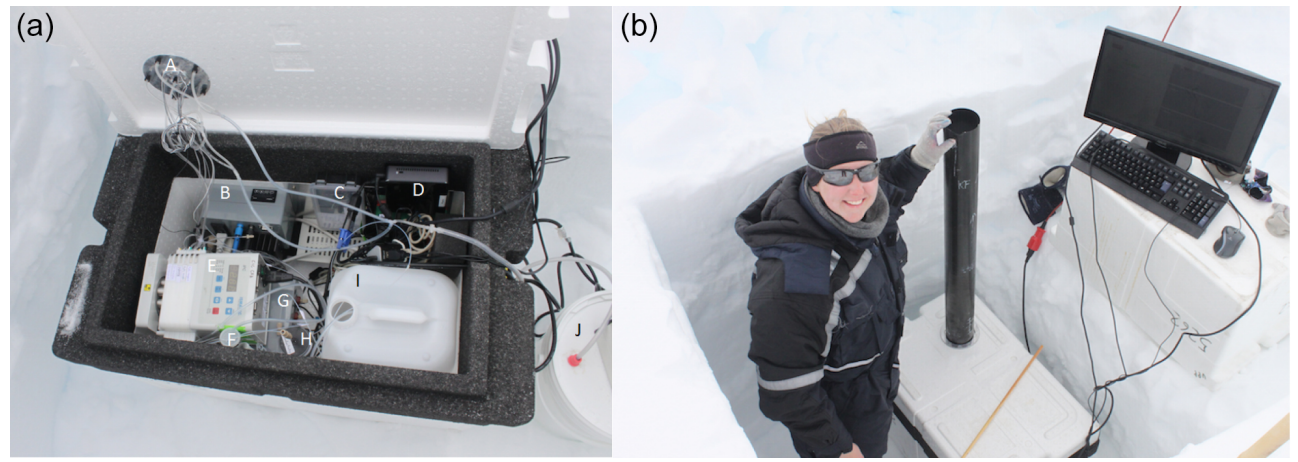

Figure 2. (a) An inside look at the LISA box. The letters in panel (a) denote the following: A - the underside of the melt head; B - the melt head temperature regulator; $\mathrm{C}$ - the temperature proportional integral derivative (PID) that stabilizes the inner temperature of the box; $\mathrm{D}$ the computer; $\mathrm{E}$ - the peristaltic pump; $\mathrm{F}$ - the debubbler; $\mathrm{G}$ - the fluorescence box (F-box); $\mathrm{H}$ - the conductivity meter; I - the chemical wastewater container; and $\mathbf{J}-$ a container for collecting waste water from the outer section of the melt head, which is located outside the LISA box. (b) LISA box during field work 2017. The snow is collected in the black liner and melted continuously, while data can be observed online on the attached screen.

meltwater (Fig. S3). The inclination prevents bubbles from entering the sample line, as the conical shape melts the different depths of the firn core at the same time and "floods" the lower part of the inner cone. The volume of the inner cone determines how much mixing happens in the sample stream before it is distributed to the analysis unit. As is done for all CFA systems to prevent contamination, the inner melt head cone melts more water for the outer part of the core than is being drained, thereby producing an overflow of inner meltwater out toward the waste drainage.

The melt head is heated by heat cartridges (HHP30, Mickenhagen $\mathrm{GmbH}$, Lüdenscheid, Germany), which are controlled by a proportional integral derivative (PID, CN7532, Omega Engineering) device ("B" in Fig. 2; Fig. S1). One of the heat cartridges has an inbuilt J-type thermocouple that provides the temperature for the PID, so that the temperature of the melt head can be regulated to obtain an optimum melt speed. The optimum melt speed is site dependent and can, thus, be varied with the density of the sample and the expected annual layer thickness.

The melt head (inner diameter of $11 \mathrm{~cm}$ to fit a $10 \mathrm{~cm}$ snow core) is made of solid aluminium, which was chosen for its low density, high thermal conductivity and excellent corrosion resistance. The inner cone is $7 \mathrm{~cm}$ higher than the deepest point of the melt head, which is $6 \mathrm{~cm}$ lower than the outer rim. There is one drainage hole in the centre of the melt head and five outer drainage holes. The inner cone volume is $3.8 \mathrm{~cm}^{3}$. Additional specifications of the melt head can be found in Table S1 in the Supplement.

The melt speed is a crucial parameter to obtain, as it is used to reconstruct the depth of the analysed sample. Several ways exists to determine melt speed in CFA systems, including encoders, lasers and image recognition (Bigler et al., 2011; Dallmayr et al., 2016; McConnell et al., 2002). The melt speed in the portable CFA developed here is sim- ply registered by simultaneously determining the amount of core left above the melt head with a ruler and the time. While this method is clearly imprecise compared with the more advanced options that exist, it is also the simplest, as no complicated electronics are necessary, only a ruler, chronometer and a notebook, thereby reducing the weight requirements.

\subsection{Temperature stabilizer of inner box}

When aiming to move a CFA to the field, it is crucial to ensure a stable temperature environment for the measurement apparatus and chemicals inside the box. Thus, a custom-built thermostat is installed inside the LISA box to ensure a stable temperature (inside the box) of between 17 and $18^{\circ} \mathrm{C}$ ("C" in Fig. 2). The thermostat and its digital display are mounted on a stainless-steel plate that is fixed on the box wall. The thermostat is connected to $200 \mathrm{~W}$ compact fan heater (FCHFGC1 series, Omega Engineering) that sits at the bottom of the LISA box and is guarded by a fence to avoid contact with the other box contents. The fan is always active to ensure that air is well mixed within the box and to distribute heat when required.

\subsection{Computer and communication devices}

To control the measurement devices, the melt head temperature and to save data, a miniature computer is mounted on the wall of the box (Fig. 2-D); it is connected to a USB hub and a RS232-to-USB converter (Digi International) that are also inside the box as well as to a screen and keyboard outside the box.

The wires for the mouse and keyboard positioned outside the box are connected via a small triangle cut in the side of the LISA box, as is the screen cable. The screen is connected via a series of adapters (VGA-HDMI and HDMI-HDMI). 


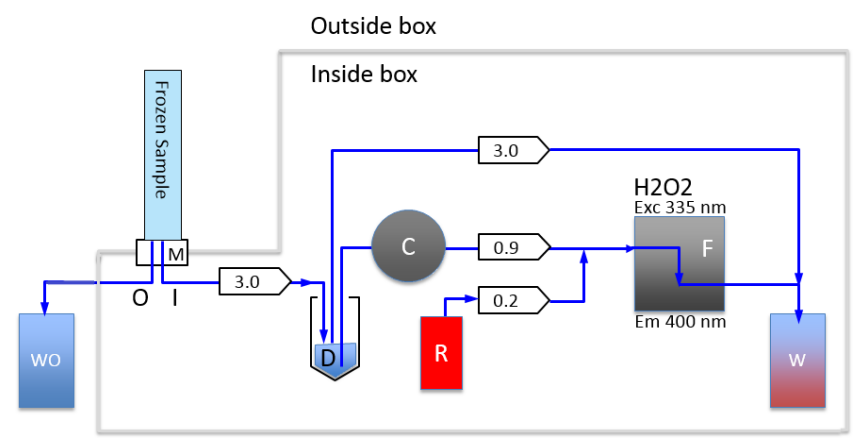

Figure 3. The continuous flow analysis (CFA) set-up for the LISA box. The frozen sample is melted on the melt head (M), and the meltwater is split into an inner uncontaminated sample line (I) and an outer possibly contaminated line $(\mathrm{O})$. The outer line is collected in a waste bucket outside the box (WO). The inner line is pumped to a debubbler (D), which is kept at a fixed volume by an overflow line. From the debubbler, the sample reaches the conductivity metre $(\mathrm{C})$ after which it is mixed with reagent $(\mathrm{R})$ prior to analysis by fluorescence $(\mathrm{F})$. The mixed water is then collected in a waste bucket (W). Active pumping is illustrated using pentagons, and the numbers within the pentagons indicate the flow rate in millilitres per minute $\left(\mathrm{mL} \mathrm{min}^{-1}\right)$.

The program that runs the CFA inside the LISA box is a custom-built LabVIEW program with an interface showing the measurements in real time; thus, a first assessment of the data can be done while in the field, allowing for an initial data quality assessment during measurement.

\subsection{Continuous flow scheme}

The overall CFA set-up for the LISA box is shown in Fig. 3 and builds on conventional CFA instruments used for the analysis of ice cores using PEEK (polyether ether ketone) connectors and PFA (perfluoroalkoxy) (1.55 mm inner diameter, $1 / 8$ inch outer diameter, IDEX) tubing (Bigler et al., 2011; Kaufmann et al., 2008).

\subsubsection{Debubbler}

An Ismatec IPC eight-channel peristaltic pump and Tygon pump tubing are used for the inner line sample transport through the CFA. A debubbler (see "F" in Fig. 2 and "D" in Fig. 3) is implemented early in the system to ensure that potential air pumped into the system or short pauses in melting do not interfere with the measurements downstream. The debubbler is a small Accuvette with one inlet line and two outlet lines. The inner meltwater part from the melt head is pumped to the debubbler at a speed of $3 \mathrm{~mL} \mathrm{~min}^{-1}$. The volume in the debubbler is controlled by one outlet line positioned at a fixed height in the debubbler that actively pumps excess meltwater/air to waste $(3 \mathrm{~mL} \mathrm{~min}-1)$ in order to ensure constant volume in the debubbler. The second outlet line is the main sample line and is positioned deep in the lower part of the debubbler. It is pumped at a speed of $1 \mathrm{~mL} \mathrm{~min}^{-1}$ (or $2 \mathrm{~mL} \mathrm{~min}^{-1}$, depending on set-up) to be collected for further analysis. As in all CFA systems, flow rates can be adjusted depending on the requirements and the number of analysis systems connected downstream.

\subsubsection{Conductivity meter}

The water is led from the debubbler to an Amber Science 3082 conductivity meter ("H" in Fig. 2 and "C" in Fig. 3) (Bigler et al., 2011). The response time (5\%-95\% of signal) of the instrument itself is just $3 \mathrm{~s}$. However, the typical measurement resolution is only on the order of $20 \mathrm{~s}$ as a result of upstream smoothing in the debubbler and melt head.

\subsubsection{Fluorescence measurements $-\mathrm{H}_{2} \mathrm{O}_{2}$}

From the conductivity meter, the sample is mixed with a reagent and measured by means of fluorescence. A custom box was built for fluorescence analysis in order to limit the space used within the LISA box (F-box; "G" in Fig. 2 and "F" in Fig. 3). The F-box allows for the determination of two chemical species by means of fluorescence and is powered by a $5 \mathrm{~V}$ power supply. The two fluorescence systems in the F-box can be independently activated or deactivated using two switches at the front of the F-box. Serial connectors and RS232 communication protocols were adopted to ensure stability when moving the box between sites in the field.

Inside the F-box, each of the two analytical lines consist of a $10 \mathrm{~mm}$ path length cuvette (176.766-QS, Hellma) and a photomultiplier tube (PMT 9111, Sens-Tech, UK) in a lighttight aluminium holder with a specific optical filter in front, depending on the desired frequency of outgoing light (Bigler et al., 2011).

In the field, we only tested the F-box for the determination of hydrogen peroxide $\left(\mathrm{H}_{2} \mathrm{O}_{2}\right)$, which is known to show clear annual signals in Greenland snow (Sigg and Neftel, 1988; Frey et al., 2006). The reagent is kept in a bottle at the bottom of the LISA box and is added to the meltwater sample at a rate of $0.14 \mathrm{~mL} \mathrm{~min}^{-1}$. The response time $(5 \%-95 \%$ of signal) of the hydrogen peroxide system is just $13 \mathrm{~s}$ if fully optimized (Röthlisberger et al., 2000); however, in a similar fashion to the conductivity, it is influenced by upstream smoothing, and the resulting response is on the order of $\sim 40 \mathrm{~s}$. A $335 \mathrm{~nm}$ LED was used to excite the sample, and detection was carried out at $400 \mathrm{~nm}$. The $\mathrm{H}_{2} \mathrm{O}_{2}$ reagent consists of $1 \mathrm{~L}$ of purified water, $0.61 \mathrm{~g}$ of 4-ethylphenol, $5 \mathrm{mg}$ of peroxidase type II, $6.18 \mathrm{~g}$ of $\mathrm{H}_{3} \mathrm{BO}_{3}, 7.46 \mathrm{~g}$ of $\mathrm{KCl}$ and $150 \mu \mathrm{L}$ of $\mathrm{NaOH}$ (30\%) (Kaufmann et al., 2008; Röthlisberger et al., 2000). The $\mathrm{H}_{2} \mathrm{O}_{2}$ reagent was prepared prior to entering the field (up to 1 month in advance) and kept frozen until just prior to use.

In addition to the $\mathrm{H}_{2} \mathrm{O}_{2}$ analysis system, the F-box is prepared for the determination of calcium. The LED for calcium analysis is $340 \mathrm{~nm}$, and the emission is determined at 
$495 \mathrm{~nm}$. The reagent used is mixed with $1 \mathrm{~mL} \mathrm{~min}^{-1}$ sample at a speed of $0.14 \mathrm{~mL} \mathrm{~min}^{-1}$; consists of $750 \mathrm{~mL}$ of purified water, $20 \mathrm{mg}$ of QUIN-2 potassium hydrate and $2.91 \mathrm{~g}$ of PIPES; and is buffered to $\mathrm{pH} 7$ by 1 to $1.5 \mathrm{~mL} \mathrm{NaOH} \mathrm{(30 \% )}$ (Kaufmann et al., 2008; Röthlisberger et al., 2000). We have successfully used the calcium reagent under normal laboratory conditions (Bigler et al., 2011) after it was frozen for months; thus, calcium should also be an option for analysis in the field, although it has not been explicitly validated under field conditions.

The mixture of reagent and sample water is collected in a $10 \mathrm{~L}$ waste bucket inside the LISA box ("I" in Fig. 2) so that it can be brought back from the field for proper chemical waste handling. With a combined flow of just $2.2 \mathrm{~mL} \mathrm{~min}^{-1}$ when analysing conductivity, peroxide and calcium, and a melt speed on the order of $3 \mathrm{~cm} \mathrm{~min}^{-1}$, the waste container will only need to be replaced after analysing approximately $130 \mathrm{~m}$ of ice.

\subsection{Vacuum pump}

The five outer lines from the melt head are each $1 / 3$ inch (Tygon R3603); however, inside the box, they are connected to just one $(1 / 2$ inch) line. This line exits from a small hole in the side of the LISA box. Here, it is tightly connected to the lid of a $5 \mathrm{~L}$ bucket ("J" in Fig. 2). A tube is also connected to the lid of the bucket, and a vacuum pump (VWR, PM27330$84.0, P_{\max }=0.3 \mathrm{bar}, 65 \mathrm{~W}$ ) is attached to the other end of the tube to ensure that the bucket constantly has a vacuum that works to quickly remove all wastewater from the melt head. During melting this vacuum will build up, and one can adjust the strength of the pull by letting some air into the bucket by releasing the lid. As this water is just melted snow and, thus, uncontaminated, it can be dumped on-site when full or collected for further analysis in home laboratories as required. The vacuum pump is powered by the same electrical supply as the LISA box.

\section{Field work}

The LISA box was tested at the EastGRIP deep ice core drilling camp $\left(75.63^{\circ} \mathrm{N}, 36.00^{\circ} \mathrm{W} ; 2708 \mathrm{~m}\right.$ a.s.l.) located near the onset of the north-east Greenland ice stream.

\subsection{Field work in 2017}

In 2017, the first set of field experiments was conducted using the LISA box under freezing conditions $\left(-20^{\circ} \mathrm{C}\right)$ outside at EastGRIP camp (see Fig. 2). The total weight of equipment brought to the field in 2017 amounted to $78 \mathrm{~kg}$ and was split into three boxes: the LISA box, and two ZARGES boxes that included several spare parts.

The LISA box was set up to only measure conductivity. We succeeded in melting several shallow snow cores from surface to about $1 \mathrm{~m}$ depth in $-20^{\circ} \mathrm{C}$ and $5 \mathrm{~m} \mathrm{~s}^{-1}$ wind con- ditions by positioning the box in a snow pit and using a small generator for energy provision. The melt head temperature was set to between +35 and $+45^{\circ} \mathrm{C}$. Snow cores were collected using $1 \mathrm{~m}$ long carbon fibre liners with a $10 \mathrm{~cm}$ inner diameter and a $1 \mathrm{~mm}$ wall thickness (called "liners") (Schaller et al., 2016). The snow cores were melted directly from the liners by holding the liner slightly above the melt head. The amount of core left above the melt head and the time were registered for about every $3 \mathrm{~cm}$ melted. Two people operated the box: one measuring the melt rate, and the other supporting the liner and evaluating the online results. Figure S3 shows the conductivity results obtained in 2017. This test confirms that the LISA box can function in freezing outside conditions.

\subsection{Field work in 2019}

In 2019, we brought a total of $63 \mathrm{~kg}$ to the EastGRIP site that was split in two boxes: the LISA box and one ZARGES box containing spare parts. Both hydrogen peroxide and conductivity were determined in several snow cores. When assembled, the LISA box weighed $50 \mathrm{~kg}$ excluding the generator. The box was operated at $+20^{\circ} \mathrm{C}$ inside the main building at the EastGRIP site. Samples were collected in liners from seven sites in northern Greenland in May and July 2019 (positions given in Table 1, map Fig. 1). The liners were stored frozen for up to 2 months prior to analysis. Most samples were analysed directly from the liners, in a similar fashion to the 2017 sampling technique, but some samples were transferred to plastic bags for storage prior to analysis. The amount of core left above the melt head was registered approximately every $100 \mathrm{~s}$, and melt speed varied between 2.3 and $3 \mathrm{~cm} \mathrm{~min}-1$. Two people operated the box: one person supporting the liner and measuring the amount of snow left during melting, and the other person evaluating the online results and checking the flow of water in the system in the LISA box.

A total of $18 \mathrm{~m}$ of snow was analysed for conductivity (Fig. 4) and hydrogen peroxide (Fig. 5) over 6 measurement days. Each $100 \mathrm{~cm}$ snow core was weighed to a precision of $10 \mathrm{~g}$, and using the $10 \mathrm{~cm}$ inner diameter of the liner, the density for each $1 \mathrm{~m}$ section was determined with an uncertainty from the scale of $<3 \mathrm{~kg} \mathrm{~m}^{-3}$. In addition, high-resolution densities were obtained from cores at the B16, B19 and B22 sites by means of computed tomography (Freitag et al., 2013; Schaller et al., 2016). It is worth noting that the two operators handling the LISA box during the 2019 field season had little previous CFA experience; thus, the successful measurements obtained demonstrate that the LISA box can also be handled by non-experts. 
Table 1. Accumulation as determined by the summer hydrogen peroxide peak measured using the LISA box for several sites in northern Greenland. Densities are estimated based on $1 \mathrm{~m}$ snow core weights. Accumulation from other sources and the time period covered by these sources (in parentheses) are also shown. The studies referenced in the table are as follows: Kjær et al. (2021) ${ }^{\mathrm{a}}$, Vallelonga et al. (2014) ${ }^{\mathrm{b}}$, Rasmussen et al. (2013) ${ }^{\mathrm{c}}$, Masson-Delmotte (2015) ${ }^{\mathrm{d}}$, Schaller et al.(2016) ${ }^{\mathrm{e}}$, Weißbach et al. $(2016)^{\mathrm{f}}$, Karlsson et al.(2020) ${ }^{\mathrm{g}}$, Nakazawa et al. $(2020)^{\mathrm{h}}$ and Kuramoto et al. $(2011)^{\mathrm{i}}$.

\begin{tabular}{|c|c|c|c|c|c|c|c|c|c|c|}
\hline \multirow{3}{*}{ Site } & \multirow{3}{*}{$\begin{array}{l}\text { Position } \\
\text { Latitude }\left({ }^{\circ} \mathrm{N}\right), \\
\text { longitude }\left({ }^{\circ} \mathrm{W}\right)\end{array}$} & \multirow{2}{*}{\multicolumn{2}{|c|}{ Density $\left(\mathrm{kg} \mathrm{m}^{-3}\right)$}} & \multicolumn{6}{|c|}{ This work } & \multirow{2}{*}{$\begin{array}{l}\text { Others } \\
\left.\mathrm{yr}^{-1}\right)\end{array}$} \\
\hline & & & & \multicolumn{6}{|c|}{ Water equivalent accumulation $\left(\mathrm{cm} \mathrm{yr}^{-1}\right)$} & \\
\hline & & $0-1 \mathrm{~m}$ & $1-2 \mathrm{~m}$ & $\begin{array}{c}2017- \\
2018\end{array}$ & $\begin{array}{c}2016- \\
2017\end{array}$ & $\begin{array}{r}2016- \\
2015\end{array}$ & $\begin{array}{c}2015- \\
2014\end{array}$ & Mean & $\mathrm{SD}$ & \\
\hline $\mathrm{B} 22$ & $\begin{array}{l}79^{\circ} 18^{\prime} 35.6^{\prime \prime}, \\
45^{\circ} 40^{\prime} 26.3^{\prime \prime}\end{array}$ & 326 & 357 & 12.52 & 18.84 & 12.25 & 15.04 & 14.67 & 2.64 & $14.5(1479-1993)^{\mathrm{f}}$ \\
\hline B19 & $\begin{array}{l}77^{\circ} 59^{\prime} 33.4^{\prime \prime} \\
36^{\circ} 23^{\prime} 32.0^{\prime \prime}\end{array}$ & $\begin{array}{l}332 \\
342\end{array}$ & $\begin{array}{l}352 \\
354\end{array}$ & $\begin{array}{l}10.89 \\
10.51\end{array}$ & $\begin{array}{l}11.96 \\
13.72\end{array}$ & $\begin{array}{r}13.28 \\
12.5\end{array}$ & $\begin{array}{l}16.01 \\
19.39\end{array}$ & $\begin{array}{l}13.03 \\
14.03\end{array}$ & $\begin{array}{r}1.91 \\
3.3\end{array}$ & $9.4(934-1993)^{f}$ \\
\hline NEEM & $\begin{array}{l}77^{\circ} 27^{\prime} \\
51^{\circ} 3.6^{\prime}\end{array}$ & $\begin{array}{l}346 \\
350 \\
352\end{array}$ & & $\begin{array}{l}16.44 \\
19.95 \\
18.51\end{array}$ & $\begin{array}{l}- \\
- \\
-\end{array}$ & $\begin{array}{l}- \\
- \\
-\end{array}$ & $\begin{array}{l}- \\
- \\
-\end{array}$ & $\begin{array}{l}16.11 \\
19.55 \\
18.14\end{array}$ & & $\begin{array}{l}23.5(1997-2014)^{\mathrm{a}}, \\
20.3(1000 \mathrm{BC}-2000)^{\mathrm{c}}, \\
20.3(1725-2011)^{\mathrm{d}}, \\
22.5(2014-2015)^{\mathrm{e}}, \\
17.6(2006-2008)^{\mathrm{i}}\end{array}$ \\
\hline B16 & $\begin{array}{l}73^{\circ} 56^{\prime} 07.9^{\prime \prime}, \\
37^{\circ} 36^{\prime} 58.2^{\prime \prime}\end{array}$ & 346 & 358 & 18.99 & 16.86 & 16.84 & - & 17.56 & 1.01 & $14.1(1640-1993)^{\mathrm{f}}$ \\
\hline $\begin{array}{l}\text { S7 EastGRIP } \\
\text { (ice stream) }\end{array}$ & $\begin{array}{l}75^{\circ} 37^{\prime} 44.4^{\prime \prime}, \\
35^{\circ} 58^{\prime} 49.3^{\prime \prime}\end{array}$ & 378 & 418 & 16.75 & 16.62 & 19.48 & - & 17.62 & 1.32 & $\begin{array}{l}11.2(1607-2011)^{\mathrm{b}}, \\
13(1694-2015)^{\mathrm{g}}, \\
14.9(2009-2016)^{\mathrm{h}}, \\
14.5(2009-2016)^{\mathrm{h}}\end{array}$ \\
\hline $\begin{array}{l}\text { S5 EastGRIP } \\
\text { (shear margin) }\end{array}$ & $\begin{array}{l}75^{\circ} 33.296^{\prime}, \\
35^{\circ} 37.377^{\prime}\end{array}$ & $\begin{array}{l}347 \\
332\end{array}$ & 367 & $\begin{array}{l}16.13 \\
16.97\end{array}$ & $\begin{array}{c}- \\
17.98\end{array}$ & $\begin{array}{r}- \\
15.39\end{array}$ & $\begin{array}{l}- \\
-\end{array}$ & $\begin{array}{l}16.13 \\
16.78\end{array}$ & 1.07 & $\begin{array}{l}14.6(1982-2015)^{\mathrm{a}}, \\
14.0(2013-2015)^{\mathrm{e}}\end{array}$ \\
\hline $\begin{array}{l}\text { S4 (50 km upstream } \\
\text { from EastGRIP) }\end{array}$ & $\begin{array}{l}75^{\circ} 16.236^{\prime} \\
37^{\circ} 00.444^{\prime}\end{array}$ & 346 & 367 & 17.48 & 15.56 & 12.56 & 13.84 & 14.86 & 1.85 & \\
\hline
\end{tabular}

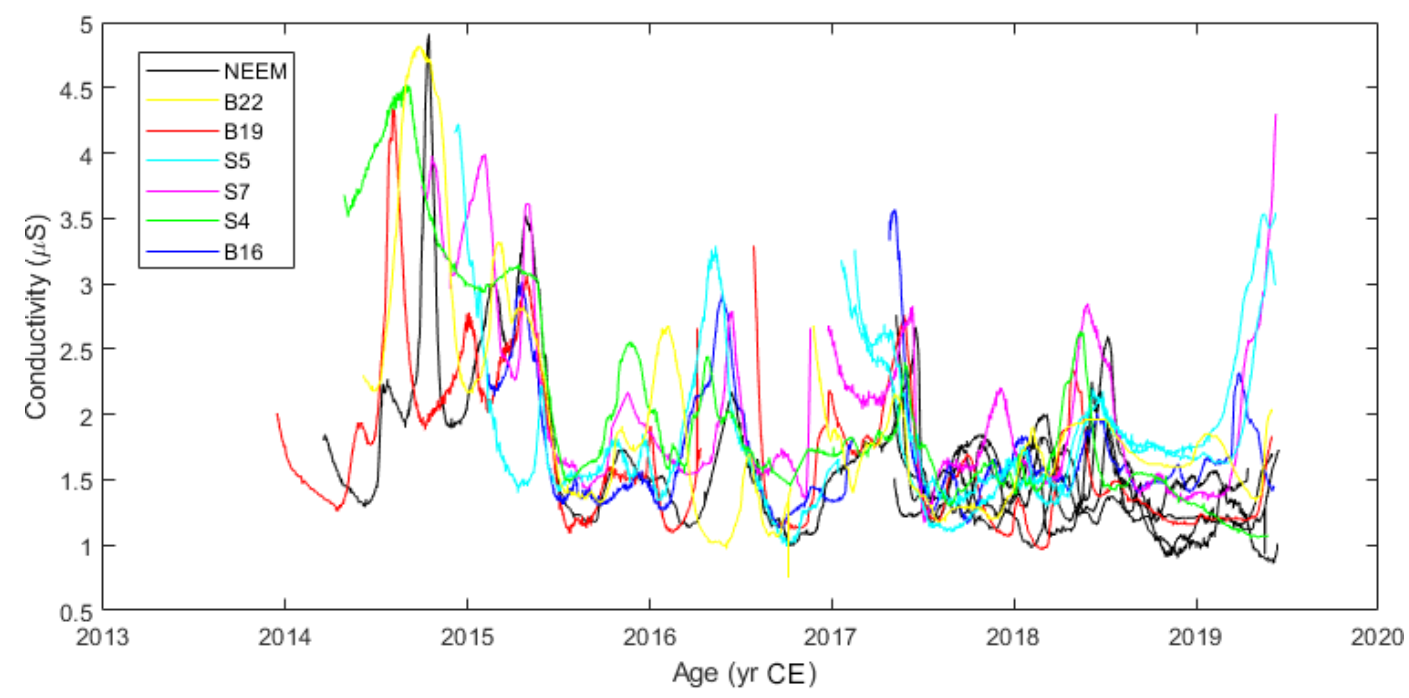

Figure 4. Conductivity for seven sites in northern Greenland on an age scale. Note the high values centred on winter 2015 , likely reflecting the eruption of the Holuhraun vent of Bárðarbunga Volcano in Iceland (29 August 2014 to 27 February 2015) (Du et al., 2019a; Schmidt et al., 2015; Gauthier et al., 2016). 


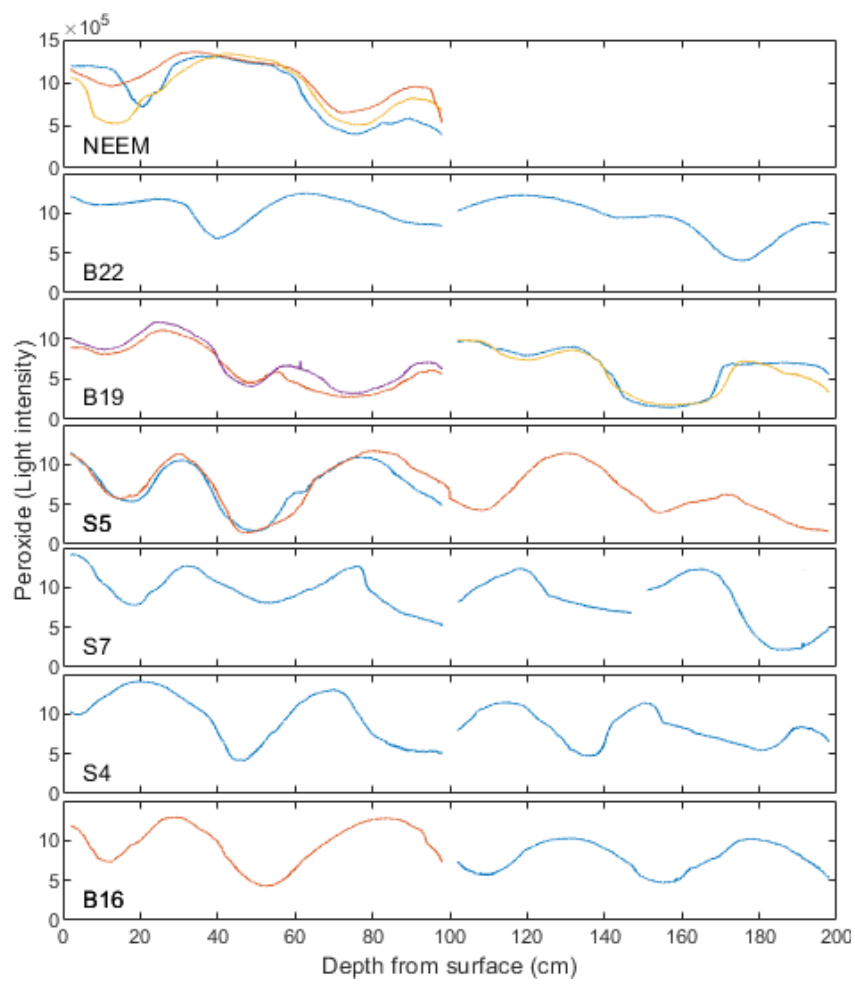

Figure 5. Hydrogen peroxide with depth for seven sites in northern Greenland (clockwise from north-west). For the NEEM, B19 and S5 sites, several cores were retrieved. Colours indicate when multiple snow cores were collected or when the top and bottom of a pit were not measured in one run. The data are not calibrated, and the $y$ axis is raw light intensities; thus, while the level reflects the hydrogen peroxide concentration, absolute values are not to be trusted.

\section{Results}

The hydrogen peroxide results obtained from the LISA box in the 2019 field season are shown in Fig. 5. Samples were analysed $1 \mathrm{~m}$ at a time, resulting in small amounts of missing data at start and end of each sample as a result of the response time in the CFA system; an exception to this was the S5 site (red line), where the deeper sample (1-2 m) was added directly after the top $1 \mathrm{~m}$ was analysed, thereby avoiding the lack of data related to the response time of the instrumentation. Despite the hydrogen peroxide data being uncalibrated, we observe annual cycles of a summer high and a winter minimum in the raw light intensity counts, as expected (Sigg and Neftel, 1988; Frey et al., 2006). It is worth noting that the resemblance between the measurements at the B19 and S5 sites, where the snow cores were retrieved just few centimetres apart, demonstrates the repeatability of the LISA box. At NEEM, samples were taken $10 \mathrm{~m}$ apart, and while one can observe the same features, the variability between the three sets of measurements is larger; moreover, with respect to the conductivity at the EastGRIP site (2017 field season), the two snow cores from the same snow pit show significant variabil- ity, reflecting that the typical wind-driven surface features operate on a metre rather than a centimetre scale and confirming the need to take multiple cores from a site with metre intervals if the aim is to establish a site's mean chemical deposition (Schaller et al., 2016; Gfeller et al., 2014; Laepple et al., 2016). An age scale was determined by linearly interpolating between $\mathrm{H}_{2} \mathrm{O}_{2}$ peaks by assuming that peak hydrogen peroxide occurs in mid-summer (Sigg and Neftel, 1988; Frey et al., 2006). In addition, the bottom age was determined using the mean annual layer thickness from all of the hydrogen peroxide peaks at that site relative to the number of centimetres since the last hydrogen peroxide peak. Thus, generating this timescale, we are assuming equal accumulation throughout the year, as is often done when dating ice cores based on just one proxy. In general, the $2 \mathrm{~m}$ core sections reach back 4-5 years depending on the site accumulation.

Using $\mathrm{H}_{2} \mathrm{O}_{2}$-based dating, we observe the expected annual peak in the conductivity (Fig. 4) centred around spring, but it is very wide and often contains multiple events. This suggests one of the following:

- Our assumption that annual layers can be dated using just the hydrogen peroxide summer peaks in central Greenland snow is inaccurate. However, while lowaccumulation sites or sites with melt layers can influence the photolysis in the snow pack and, thus, the $\mathrm{H}_{2} \mathrm{O}_{2}$ stored within (Sigg and Neftel, 1988; Frey et al., 2006), we are dealing with relative high and dry accumulation; hence, we are confident that using $\mathrm{H}_{2} \mathrm{O}_{2}$ for annual layer recognition is a reasonable approach.

- Using conductivity in spring for dating snow and ice cores is not the best option for timescale reconstruction in northern Greenland surface snow.

- The seasonal timing of conductivity deposition over Greenland varies between sites. Conductivity in Greenland snow and ice is mostly driven by $\mathrm{H}^{+}$.

However, spatial variability in the annual peak conductivity deposition is not unexpected, as the conductivity in snow and ice can also be highly influenced by forest fire acids and/or salt content, showing seasonal peaks that may vary from site to site. From 14 August 2014 until 15 February 2015 the volcanic explosivity index (VEI) 1 eruption of the Holuhraun vent of Bárðarbunga Volcano occurred (Du et al., 2019a, b; Schmidt et al., 2015; Gauthier et al., 2016), and we find enhanced conductivity reaching almost $5 \mu \mathrm{S}$ between June 2014 and May 2015, resembling the Holuhraun eruption (Fig. 4). This suggests that our dating is slightly off but is generally in agreement with the expected time period. This is acceptable when considering that the dating of the core is assuming constant accumulation throughout the year, and it proves that the box can also be used for identifying volcanic reference horizons that are often used to cross-date individual ice cores. Below, we discuss the results from the LISA 
box further with focus on their application to reconstruct accumulation in northern Greenland.

\subsection{Reconstructing spatial variability of accumulation in northern Greenland}

Only a few accumulation estimates exist for northern Greenland, and most are older studies from the mid-1990s (Montgomery et al., 2018; Schaller et al., 2016; Weißbach et al., 2016). By combining the age scale based on the hydrogen peroxide results with the obtained $1 \mathrm{~m}$ density estimates, annual estimates of water equivalent accumulation were derived (Table 1, Fig. S4) for the seven sites in northern Greenland. When the years overlapped between the first and second metre, the density used was a combination of the top and bottom estimates based on the relative amount of the year falling into each. At an annual resolution, the metre-averaged densities used in this study overestimated the accumulation by $4.7 \%$ on average compared with the high-resolution snow liner densities performed at B16, B19 and B22 using portable computer tomography (Freitag et al., 2013). Table 1 also shows earlier accumulation estimates from the sites, when available (Schaller et al., 2016; Weißbach et al., 2016; Vallelonga et al., 2014; Rasmussen et al., 2013; Masson-Delmotte et al., 2015; Kuramoto et al., 2011; Karlsson et al., 2020; Nakazawa et al., 2020; Kjær et al., 2021). Note that the accumulation estimates only rarely temporally overlap with previous estimates.

We do not observe any consistent increase or decrease at any of the sites compared with earlier estimates. The B22 site in northernmost Greenland is equivalent with earlier estimates within uncertainties, whereas we find higher accumulation for the B19 site (Weißbach et al., 2016). For NEEM, further to the west, we find much lower accumulation compared with earlier estimates. Our reconstructed accumulation at NEEM relies on just 1 year (summer 2017-summer 2018), which is known to have been a year of low accumulation in northern Greenland, whereas earlier estimates rely on several hundreds of years (Masson-Delmotte et al., 2015; Rasmussen et al., 2013). For the B16 site and the sites closer to EastGRIP (S5 and S7), our results from the cores retrieved in 2019 ( 14.9-17.6 cm w.e. annually) are considerably higher than the $11.2 \mathrm{~cm}$ w.e. previously observed in the 400-year Northeast Greenland Ice Stream (NEGIS) ice core obtained at the EastGRIP site in 2012 (Vallelonga et al., 2014), and they are also larger than the more recent estimates from radar (13 cm w.e.; Karlsson et al., 2020), firn cores (13.7 and 14.6; Kjær et al., 2021), snow pits (14.6 cm w.e.; Nakazawa et al., 2020) and the $14.1 \mathrm{~cm}$ w.e. observed at the B16 site (Weißbach et al., 2016). Our results from EastGRIP 2017 using the conductivity (see the Supplement) are more consistent with previous results.

We highlight that variability between individual years for sites such as B22 and S4 is larger than their difference from previous estimates from the area; moreover, for the sites where more snow cores were obtained (EastGRIP-2017, NEEM, S5 and B19), the difference in accumulation between individual years is up to $20 \%$ (Fig. S4). Other studies have also shown a similar variability investigating shorter firn cores (NEEM-25\%, EastGRIP-30\%; Kjær et al., 2021). This illustrates the need to carry out several measurements over time at each site if aiming to reconstruct the climatic mean accumulation or to use firn cores to do so. We also note that using the high-resolution CT scanning densities instead of the $1 \mathrm{~m}$ mean densities would not alter the above observations.

In the following, we speculate on the Arctic Oscillation (AO) and North Atlantic Oscillation (NAO) impact on our records compared with previous estimates. The years 20162018 were observed to have high NAO and AO winter indexes, which have previously been suggested to enhance winter precipitation in the north-east and to be anticorrelated with precipitation in the north-west (Koyama and Stroeve, 2019). The years analysed here also had high summer accumulation based on satellite estimates in the north-eastern area. Thus, our generally higher accumulation east of the ice divide compared with previous estimates of accumulation could be partly explained by the atmospheric settings, which would simultaneously help explain the low estimates at NEEM. We highlight that the above is indeed speculative and that longer records are needed to firmly conclude on the impact of the $\mathrm{AO}$ and/or NAO on accumulation.

\section{Lessons learnt and future improvements of the LISA box}

While we have shown the results from the first version of a LISA box, we will continue development for a number of reasons. In this section, we discuss some of the lessons learnt and suggest future improvements.

During field work in 2019, the box's internal flow was accidently not completely emptied of water prior to storage. The instrument was later stored under freezing conditions, and the expansion of the water during freezing resulted in a broken flow cell in the F-box. While this can be avoided by simply ensuring the box is emptied of water when ending analysis, we will look into the optimization of the entire flow design in order to ensure that such damage can be avoided or at least easily diagnosed.

In the case of faulty analysis or blockages in the flow line, the sample and full frame can be lifted off the melt head and restarted again once the issue is fixed; however, this will result in some sample loss $(1-3 \mathrm{~cm})$. A benefit of moving CFA to the field with this instrument is the option of obtaining new samples (especially snow cores) and being able to re-analyse - something that is not possible when carrying out analysis in the home laboratory.

During melting of the snow cores, the percolation of up to $3 \mathrm{~cm}$ of water into the snow column above the melt head was 
observed. This causes additional smoothing and depth uncertainty in the data obtained by the LISA box. The melt head design could be improved to reduce percolation and ease the overflow decontamination procedure - for example, by having extra drain holes and slits or channels etched into the melt head surface radiating outward from the centre, both in the inner cone and in the outer waste surface. These slits would provide an "escape" path for the liquid meltwater and would avoid it being sucked in by air pockets in the porous firn that is yet to be melted.

Further, the main uncertainty in the reconstructed accumulation from analysis with the LISA box is the result of uncertainties in the depth registration. One could instead use image recognition in combination with a camera to identify the melt speed, as is done in the Desert Research Institute (DRI) Reno CFA, or a continuous laser distance for the depth registration, as done in other CFA laboratories (Dallmayr et al., 2016); however, such systems will complicate the box and make it less practical for use by laypeople. The camera pattern recognition is further hampered by the percolation of meltwater, but it would be the better option if LISA were to be used on ice samples rather than snow. With a more stable frame, perhaps a laser depth registration system could be implemented.

In CFA systems, the melt speed is often stabilized by adding a weight on top of the sample to hinder the slowdown of melt speed towards the end of melting (Bigler et al., 2011; Severi et al., 2015). For the analysis carried out here, we worked on snow samples that would have been compacted if such a weight was added; furthermore, we did not observe any notable slowdown in the melt speed with the melt head temperature settings and the resolution of the depth registered. However, for more solid firn and snow samples, adding such a weight would be an option for the portable CFA. If a firn or ice core was analysed, another option would be to stack the following core once $\sim 20 \mathrm{~cm}$ is left of the previous core. This, in addition to stabilizing the melt speed, would avoid the loss of a small amount of sample when starting and ending measurements for each subsample.

Finally, we acknowledge that basing the annual layers on more than just one chemical species would increase the accuracy of accumulation estimates and could diminish the overall variability in the resulting data. As the LISA box has the option of two fluorescence lines, it would be easy to add either calcium or ammonium CFA methods (Bigler et al., 2011; Röthlisberger et al., 2000). Another addition could be insoluble dust by means of Abakus, as is often done in CFA. Further discrete subsampling from either the melt head waste line or an additional internal line is also a possibility, and such discrete samples may be useful for later analysis of proxies requiring more advanced set-up such as inductively coupled plasma mass spectrometry (ICP-MS) or ion chromatography (IC) in home laboratories.

While we have proven the LISA box in freezing but relatively dry Greenland conditions, it remains to be tested under other climatic conditions, such as in high-altitude glaciers and colder Antarctic conditions. As the box is temperature regulated, if enough energy is delivered to keep the box running at set temperatures, the cold temperatures in Antarctica should not in principle cause additional complications. However, the energy consumption may increase, making the operation heavier in terms of gasoline for the generator, and one may consider moving the outside pump used to generate vacuum and the subsequent waste container into the warmth of the insulated box, despite this enhancing its dimensions. Additionally, the more static air could damage some of the electronic components, and this remains to be tested. At high altitude where the pressure is low, the balance on the flow lines could be altered using the ability to adjust flow rates to overcome pressure drop. We note that the box is quite sturdy and that the internal parts are secured well; thus, in places were transportation uphill cannot take place by helicopter or plane, the box could be safely transported by yak, oxen or sledges. At coastal foggy field sites, one could experience riming of the box, and one should consider how to best remove this from the outside of the box. As always, when embarking on field work, we recommend carrying out proper testing in similar conditions prior to deployment.

\section{Conclusions}

We have developed a lightweight in situ analysis (LISA) portable CFA system, and we have proven that it can work in the deep field at freezing temperatures $\left(-20^{\circ} \mathrm{C}\right)$ to constrain snow pack hydrogen peroxide, conductivity and, if density is also known, accumulation. The field work in 2017 shows that the box can work outside, and the 2019 field work proves that it can be operated by scientists with limited or no prior CFA experience. Thus, with this first prototype of the LISA box, we have a portable, practical and prolific prototype. We suggest some further optimizations to this first version of the LISA box: (1) the inclusion of additional analysis instruments to better constrain the annual layers, such as calcium, ammonium, insoluble dust and/or the collection of discrete samples to be analysed in home laboratories for analysis using methods such as IC or ICP-MS; (2) the improvement of the frame used to hold the sample during analysis and the depth registration system; and (3) the limitation of percolation and, thus, sample smoothing by further optimization of the melt head.

With the current version of the portable CFA system, we have reconstructed accumulation in northern central Greenland, an area where only few previous constrains exist; thus, we have added recent accumulation data for seven sites that can be used as ground truth for satellite or radar reconstructions of accumulation or to assess precipitation in models covering the region. We found an increase in accumulation east of the divide compared with previous accumulation estimates and a higher accumulation at the NEEM site west 
of the ice divide than those previously reported. We propose that these differences stem from the fact that the compared records do not always overlap in time and from the natural variability in accumulation, both between years and spatially. We note that local topography close to the EastGRIP ice core drilling site could also explain part of the difference compared with earlier accumulation estimates.

We observe a clear signal of the Holuhraun eruption as a layer of enhanced conductivity deposited in the snow cores between June 2014 and May 2015 at all sites, with the exception of NEEM, where our records do not extend far enough back in time. Thus, our results suggest that acid deposition from the Holuhraun 2014 eruption is widespread in northern Greenland.

With its lightweight and ease of use, we expect that the LISA system, as it stands, could also be used in smaller-scale polar field operations and may add to the kind of data that are reconstructed from the field.

Data availability. The following files will be made available free of charge from https://www.pangaea.de (last access: 9 August 2021) and can be provided by the authors upon request in the meantime: reconstructed accumulation and density for the $2 \mathrm{~m}$ snow profiles, and hydrogen peroxide and conductivity with depth and age (.xls).

Supplement. The supplement related to this article is available online at: https://doi.org/10.5194/tc-15-3719-2021-supplement.

Author contributions. The paper was written using contributions from all authors. All authors approved the final version of the paper. LLH, PV, HAK, NM and MS carried out the initial development of the LISA box. LLH, HK and PV collected the samples during the 2017 field season and undertook initial testing of the box. HK and MS collected and analysed the snow samples using the LISA box in 2017. ZY, IK, MH, SK and JF collected samples from northern Greenland sites as part of the NGT (North Greenland Traverse) during the 2019 field season. ZY and IK ran the samples using the LISA box at the EastGRIP site in 2019, and MH and JF analysed the samples for densities. HK and LLH carried out the annual layer counting and reconstructed the accumulation for cores retrieved in 2019 and 2017 respectively, and HK undertook further analysis of the accumulation.

Competing interests. The authors declare that they have no conflict of interest.

Disclaimer. Publisher's note: Copernicus Publications remains neutral with regard to jurisdictional claims in published maps and institutional affiliations.
Acknowledgements. We would like to thank Mayu Lund, Romain Duphil, Jens Christian Hillerup, Angelika Humbert and Ole Zeising for assisting in the field. The Alfred Wegener Institute (AWI) operates the Polar 5 and Polar 6 research aircraft. AWI funded the ExNGT_PpRES_2019 flight campaign with Polar 5 to visit the NEEM, B16, B19, B20, B22 and B27/28 sites. We thank Daniel Steinhage (AWI) and the Basler crew for their support. We acknowledge EastGRIP for hosting us.

EGRIP is directed and organized by the Centre for Ice and Climate at the Niels Bohr Institute, University of Copenhagen. It is supported by funding agencies and institutions in Denmark (A. P. Møller Foundation, University of Copenhagen), USA (US National Science Foundation, Office of Polar Programs), Germany (Alfred Wegener Institute, Helmholtz Centre for Polar and Marine Research), Japan (National Institute of Polar Research and Arctic Challenge for Sustainability), Norway (University of Bergen and Trond Mohn Foundation), Switzerland (Swiss National Science Foundation), France (French Polar Institute Paul-Emile Victor, Institute for Geosciences and Environmental research), Canada (University of Manitoba) and China (Chinese Academy of Sciences and Beijing Normal University).

The research leading to these results has received funding from the European Research Council under the European Community's Seventh Framework programme, (FP7/2007-2013)/ERC grant agreement no. 610055 as part of the ice2ice project, and from the European Union's Horizon 2020 Research and Innovation programme, under grant agreement no. 820970 as part of the TiPES project. This paper is TiPES publication no. 49. Additional support was received from the Villum Investigator Project IceFlow (grant no. 16572).

Financial support. This research has been supported by the Alfred Wegener Institute, Helmholtz Centre for Polar and Marine Research (grant no. ExNGT_PpRES_2019), the A.P. Møller og Hustru Chastine Mc-Kinney Møllers Fond til almene Formaal (grant no. EastGRIP), the H2020 European Research Council (grant no. 610055), the Horizon 2020 Framework programme, H2020 Excellent Science (TiPES; grant no. 820970) and the Villum Fonden (grant no. 16572).

Review statement. This paper was edited by Joel Savarino and reviewed by two anonymous referees.

\section{References}

Bamber, J.: Greenland 5 km DEM, Ice Thickness, and Bedrock Elevation Grids, Version 1, NASA National Snow and Ice Data Center Distributed Active Archive Center [data set], Boulder, Colorado, USA, https://doi.org/10.5067/01A10Z9BM7KP, 2001.

Bamber, J. L., Layberry, R. L., and Gogineni, S. P.: A new ice thickness and bed data set for the Greenland ice sheet: 1. Measurement, data reduction, and errors, J. Geophys. Res., 106, 3377333780, https://doi.org/10.1029/2001JD900054, 2001.

Bigler, M., Svensson, A., Kettner, E., Vallelonga, P., Nielsen, M. E., and Steffensen, J. P.: Optimization of High-Resolution Continuous Flow Analysis for Transient Climate Sig- 
nals in Ice Cores, Environ. Sci. Technol., 45, 4483-4489, https://doi.org/10.1021/es200118j, 2011.

Dallmayr, R., Goto-Azuma, K., Kjær, H. A., Azuma, N., Takata, M., Schüpbach, S., and Hirabayashi, M.: A HighResolution Continuous Flow Analysis System for Polar Ice Cores, Bulletin of Glaciological Research, 34, 11-20, https://doi.org/10.5331/bgr.16R03, 2016.

Du, Z., Xiao, C., Zhang, Q., Handley, M. J., Mayewski, P. A., and Li, C.: Relationship between the 2014-2015 Holuhraun eruption and the iron record in the East GRIP snow pit, Arct. Antarct. Alp. Res., 51, 290-298, https://doi.org/10.1080/15230430.2019.1634441, 2019a.

Du, Z., Xiao, C., Zhang, Q., Li, C., Wang, F., Liu, K., and Ma, X.: Climatic and environmental signals recorded in the EGRIP snowpit, Greenland, Environ. Earth Sci., 78, 170, https://doi.org/10.1007/s12665-019-8177-4, 2019b.

Freitag, J., Kipfstuhl, S., and Laepple, T.: Core-scale radioscopic imaging: a new method reveals densitycalcium link in Antarctic firn, J. Glaciol., 59, 1009-1014, https://doi.org/10.3189/2013JoG13J028, 2013.

Frey, M. M., Bales, R. C., and McConnell, J. R.: Climate sensitivity of the century-scale hydrogen peroxide $\left(\mathrm{H}_{2} \mathrm{O}_{2}\right)$ record preserved in 23 ice cores from West Antarctica, J. Geophys. Res., 111, D21301, https://doi.org/10.1029/2005JD006816, 2006.

Gauthier, P.-J., Sigmarsson, O., Gouhier, M., Haddadi, B., and Moune, S.: Elevated gas flux and trace metal degassing from the 2014-2015 fissure eruption at the Bárðarbunga volcanic system, Iceland, J. Geophys. Res.-Sol. Ea., 121, 1610-1630, https://doi.org/10.1002/2015JB012111, 2016.

Gfeller, G., Fischer, H., Bigler, M., Schüpbach, S., Leuenberger, D., and Mini, O.: Representativeness and seasonality of major ion records derived from NEEM firn cores, The Cryosphere, 8, 1855-1870, https://doi.org/10.5194/tc-8-1855-2014, 2014.

Karlsson, N. B., Razik, S., Hörhold, M., Winter, A., Steinhage, D., Binder, T., and Eisen, O.: Surface accumulation in Northern Central Greenland during the last 300 years, Ann. Glaciol., 61, 214224, https://doi.org/10.1017/aog.2020.30, 2020.

Kaufmann, P. R., Federer, U., Hutterli, M. A., Bigler, M., Schüpbach, S., Ruth, U., Schmitt, J., and Stocker, T. F.: An Improved Continuous Flow Analysis System for High-Resolution Field Measurements on Ice Cores, Environ. Sci. Technol., 42, 80448050, https://doi.org/10.1021/es8007722, 2008.

Kjær, H. A., Zens, P., Edwards, R., Olesen, M., Mottram, R., Lewis, G., Terkelsen Holme, C., Black, S., Holst Lund, K., Schmidt, M., Dahl-Jensen, D., Vinther, B., Svensson, A., Karlsson, N., Box, J. E., Kipfstuhl, S., and Vallelonga, P.: Recent North Greenland temperature warming and accumulation, The Cryosphere Discuss. [preprint], https://doi.org/10.5194/tc-2020-337, 2021.

Koyama, T. and Stroeve, J.: Greenland monthly precipitation analysis from the Arctic System Reanalysis (ASR): 2000-2012, Polar Sci., 19, 1-12, https://doi.org/10.1016/j.polar.2018.09.001, 2019.

Kuramoto, T., Goto-Azuma, K., Hirabayashi, M., Miyake, T., Motoyama, H., Dahl-Jensen, D., and Steffensen, J. P.: Seasonal variations of snow chemistry at NEEM, Greenland, Ann. Glaciol., 52, 193-200, https://doi.org/10.3189/172756411797252365, 2011.

Laepple, T., Hörhold, M., Münch, T., Freitag, J., Wegner, A., and Kipfstuhl, S.: Layering of surface snow and firn at Kohnen Station, Antarctica: Noise or seasonal signal?, J. Geophys. Res.-
Earth, 121, 1849-1860, https://doi.org/10.1002/2016JF003919, 2016.

Legrand, M. and Mayewski, P.: Glaciochemistry of polar ice cores: A review, Rev. Geophys., 35, 219-243, https://doi.org/10.1029/96RG03527, 1997.

Masson-Delmotte, V., Steen-Larsen, H. C., Ortega, P., Swingedouw, D., Popp, T., Vinther, B. M., Oerter, H., Sveinbjornsdottir, A. E., Gudlaugsdottir, H., Box, J. E., Falourd, S., Fettweis, X., Gallée, H., Garnier, E., Gkinis, V., Jouzel, J., Landais, A., Minster, B., Paradis, N., Orsi, A., Risi, C., Werner, M., and White, J. W. C.: Recent changes in north-west Greenland climate documented by NEEM shallow ice core data and simulations, and implications for past-temperature reconstructions, The Cryosphere, 9, 14811504, https://doi.org/10.5194/tc-9-1481-2015, 2015.

McConnell, J. R., Lamorey, G. W., Lambert, S. W., and Taylor, K. C.: Continuous Ice-Core Chemical Analyses Using Inductively Coupled Plasma Mass Spectrometry, Environ. Sci. Technol., 36, 7-11, https://doi.org/10.1021/es011088z, 2002.

Montgomery, L., Koenig, L., and Alexander, P.: The SUMup dataset: compiled measurements of surface mass balance components over ice sheets and sea ice with analysis over Greenland, Earth Syst. Sci. Data, 10, 1959-1985, https://doi.org/10.5194/essd-10-1959-2018, 2018.

Nakazawa, F., Nagatsuka, N., Hirabayashi, M., Goto-Azuma, K., Steffensen, J. P., and Dahl-Jensen, D.: Variation in recent annual snow deposition and seasonality of snow chemistry at the east Greenland ice core project (EGRIP) camp, Greenland, Polar Sci., 27, 100597, https://doi.org/10.1016/j.polar.2020.100597, 2020.

NEEM community members: Eemian interglacial reconstructed from a Greenland folded ice core, Nature, 493, 489-494, https://doi.org/10.1038/nature11789, 2013.

Philippe, M., Tison, J.-L., Fjøsne, K., Hubbard, B., Kjær, H. A., Lenaerts, J. T. M., Drews, R., Sheldon, S. G., De Bondt, K., Claeys, P., and Pattyn, F.: Ice core evidence for a 20th century increase in surface mass balance in coastal Dronning Maud Land, East Antarctica, The Cryosphere, 10, 2501-2516, https://doi.org/10.5194/tc-10-2501-2016, 2016.

Rasmussen, S. O., Abbott, P. M., Blunier, T., Bourne, A. J., Brook, E., Buchardt, S. L., Buizert, C., Chappellaz, J., Clausen, H. B., Cook, E., Dahl-Jensen, D., Davies, S. M., Guillevic, M., Kipfstuhl, S., Laepple, T., Seierstad, I. K., Severinghaus, J. P., Steffensen, J. P., Stowasser, C., Svensson, A., Vallelonga, P., Vinther, B. M., Wilhelms, F., and Winstrup, M.: A first chronology for the North Greenland Eemian Ice Drilling (NEEM) ice core, Clim. Past, 9, 2713-2730, https://doi.org/10.5194/cp-92713-2013, 2013.

Röthlisberger, R., Bigler, M., Hutterli, M., Sommer, S., Stauffer, B., Junghans, H. G., and Wagenbach, D.: Technique for Continuous High-Resolution Analysis of Trace Substances in Firn and Ice Cores, Environ. Sci. Technol., 34, 338-342, https://doi.org/10.1021/es9907055, 2000.

Schaller, C. F., Freitag, J., Kipfstuhl, S., Laepple, T., Steen-Larsen, H. C., and Eisen, O.: A representative density profile of the North Greenland snowpack, The Cryosphere, 10, 1991-2002, https://doi.org/10.5194/tc-10-1991-2016, 2016.

Schmidt, A., Leadbetter, S., Theys, N., Carboni, E., Witham, C. S., Stevenson, J. A., Birch, C. E., Thordarson, T., Turnock, S., Barsotti, S., Delaney, L., Feng, W., Grainger, R. G., Hort, M. C., Höskuldsson, Á., Ialongo, I., Ilyinskaya, E., Jóhannsson, T., 
Kenny, P., Mather, T. A., Richards, N. A. D., and Shepherd, J.: Satellite detection, long-range transport, and air quality impacts of volcanic sulfur dioxide from the 2014-2015 flood lava eruption at Bárðarbunga (Iceland), J. Geophys. Res.-Atmos., 120, 9739-9757, https://doi.org/10.1002/2015JD023638, 2015.

Schüpbach, S., Fischer, H., Bigler, M., Erhardt, T., Gfeller, G., Leuenberger, D., Mini, O., Mulvaney, R., Abram, N. J., Fleet, L., Frey, M. M., Thomas, E., Svensson, A., Dahl-Jensen, D., Kettner, E., Kjaer, H., Seierstad, I., Steffensen, J. P., Rasmussen, S. O., Vallelonga, P., Winstrup, M., Wegner, A., Twarloh, B., Wolff, K., Schmidt, K., Goto-Azuma, K., Kuramoto, T., Hirabayashi, M., Uetake, J., Zheng, J., Bourgeois, J., Fisher, D., Zhiheng, D., Xiao, C., Legrand, M., Spolaor, A., Gabrieli, J., Barbante, C., Kang, J.-H., Hur, S. D., Hong, S. B., Hwang, H. J., Hong, S., Hansson, M., Iizuka, Y., Oyabu, I., Muscheler, R., Adolphi, F., Maselli, O., McConnell, J., and Wolff, E. W.: Greenland records of aerosol source and atmospheric lifetime changes from the Eemian to the Holocene, Nat. Commun., 9, 1476, https://doi.org/10.1038/s41467-018-03924-3, 2018.

Severi, M., Becagli, S., Traversi, R., and Udisti, R.: Recovering Paleo-Records from Antarctic Ice-Cores by Coupling a Continuous Melting Device and Fast Ion Chromatography, Anal. Chem., 87, 11441-11447, https://doi.org/10.1021/acs.analchem.5b02961, 2015.

Sigg, A. and Neftel, A.: Seasonal Variations in Hydrogen Peroxide in Polar Ice Cores, Ann. Glaciol., 10, 157-162, https://doi.org/10.3189/S0260305500004353, 1988.

Svensson, A., Andersen, K. K., Bigler, M., Clausen, H. B., DahlJensen, D., Davies, S. M., Johnsen, S. J., Muscheler, R., Parrenin, F., Rasmussen, S. O., Röthlisberger, R., Seierstad, I., Steffensen, J. P., and Vinther, B. M.: A 60000 year Greenland stratigraphic ice core chronology, Clim. Past, 4, 47-57, https://doi.org/10.5194/cp-4-47-2008, 2008.
Vallelonga, P., Christianson, K., Alley, R. B., Anandakrishnan, S., Christian, J. E. M., Dahl-Jensen, D., Gkinis, V., Holme, C., Jacobel, R. W., Karlsson, N. B., Keisling, B. A., Kipfstuhl, S., Kjær, H. A., Kristensen, M. E. L., Muto, A., Peters, L. E., Popp, T., Riverman, K. L., Svensson, A. M., Tibuleac, C., Vinther, B. M., Weng, Y., and Winstrup, M.: Initial results from geophysical surveys and shallow coring of the Northeast Greenland Ice Stream (NEGIS), The Cryosphere, 8, 1275-1287, https://doi.org/10.5194/tc-8-1275-2014, 2014.

Weißbach, S., Wegner, A., Opel, T., Oerter, H., Vinther, B. M., and Kipfstuhl, S.: Spatial and temporal oxygen isotope variability in northern Greenland - implications for a new climate record over the past millennium, Clim. Past, 12, 171-188, https://doi.org/10.5194/cp-12-171-2016, 2016.

Winstrup, M., Svensson, A. M., Rasmussen, S. O., Winther, O., Steig, E. J., and Axelrod, A. E.: An automated approach for annual layer counting in ice cores, Clim. Past, 8, 1881-1895, https://doi.org/10.5194/cp-8-1881-2012, 2012.

Winstrup, M., Vallelonga, P., Kjær, H. A., Fudge, T. J., Lee, J. E., Riis, M. H., Edwards, R., Bertler, N. A. N., Blunier, T., Brook, E. J., Buizert, C., Ciobanu, G., Conway, H., Dahl-Jensen, D., Ellis, A., Emanuelsson, B. D., Hindmarsh, R. C. A., Keller, E. D., Kurbatov, A. V., Mayewski, P. A., Neff, P. D., Pyne, R. L., Simonsen, M. F., Svensson, A., Tuohy, A., Waddington, E. D., and Wheatley, S.: A 2700-year annual timescale and accumulation history for an ice core from Roosevelt Island, West Antarctica, Clim. Past, 15, 751-779, https://doi.org/10.5194/cp-15-7512019, 2019. 